\title{
Methods of appointment and qualifications of club doctors and physiotherapists in English professional football: some problems and issues
}

I Waddington, M Roderick, R Naik

\begin{abstract}
Objective-To examine the methods of appointment, experience, and qualifications of club doctors and physiotherapists in professional football.

Methods-Semistructured tape recorded interviews with 12 club doctors, 10 club physiotherapists, and 27 current and former players. A questionnaire was also sent to 90 club doctors; 58 were returned. Results-In almost all clubs, methods of appointment of doctors are informal and reflect poor employment practice: posts are rarely advertised and many doctors are appointed on the basis of personal contacts and without interview. Few club doctors had prior experience or qualifications in sports medicine and very few have a written job description. The club doctor is often not consulted about the appointment of the physiotherapist; physiotherapists are usually appointed informally, often without interview, and often by the manager without involving anyone who is qualified in medicine or physiotherapy. Half of all clubs do not have a qualified (chartered) physiotherapist; such unqualified physiotherapists are in a weak position to resist threats to their clinical autonomy, particularly those arising from managers' attempts to influence clinical decisions.
\end{abstract}

Conclusions-Almost all aspects of the appointment of club doctors and physiotherapists need careful re-examination. (Br 7 Sports Med 2001;35:48-53)

Keywords: football clubs; doctors; physiotherapists; qualifications

Although there is a very substantial literature on the clinical management of sports related injuries, literature on the role of the club or team doctor is rather more limited, although it has begun to grow significantly in the last decade or so. In 1991, the American College of Sports Medicine published its Guidelines for the Team Physician, ${ }^{1}$ while Mellion and Walsh ${ }^{2}$ have provided a useful general description of the role of the team doctor. In relation to specific sports, Lynch and Carcasona ${ }^{3}$ and Crane ${ }^{4}$ have outlined the role of the club doctor in football (soccer), while Macleod, ${ }^{5}$ Kennedy ${ }^{6}$ and Davies $^{7}$ have described the role of the club doctor in rugby union. $\mathrm{Smith}^{8}$ has drawn attention to the importance of team doctors and crowd doctors in professional football having appro- priate specialist qualifications, and Dodds, ${ }^{9}$ writing from the perspective of a medically qualified international hockey player, has sought to define what a team expects from its doctor. In describing the role of the club or team physician, several authors have drawn attention to the possible conflict of interests between the doctor's responsibilities to the individual player as patient and to the team or club, ${ }^{410}$ while Macauley ${ }^{11}$ has recently suggested that the increasing commercialisation of sport may result in increasing pressure on doctors to treat or rehabilitate players in a manner that they find unacceptable, or to allow a player to return to play sooner than the doctor may wish. A related problem, which has been considered by several writers, is that of the degree to which, within the context of club medical practice, information should remain confidential to the doctor-patient relationship. $^{2412}$

Useful though this literature is, most of it is prescriptive: it describes not how club doctors actually behave in the real world but how, in an ideal world, they ought to behave, and, in this respect, most of the literature is not empirically grounded. Moreover, insofar as this literature is empirically grounded, it tends to be based on personal experiences of individual club doctors, rather than on the systematic collection of data from a more representative sample.

The data reported here formed part of a larger study designed to help fill this gap and to provide a basis for appropriate recommendations designed to improve the quality of care in professional football clubs in England. That broader study investigated a number of aspects of the work of club doctors and physiotherapists, including the ways in which they dealt, on a day to day basis, with the potential conflicts of interest and confidentiality issues outlined above. ${ }^{1314}$ The central focus of this paper is the qualifications, experience, and methods of appointment of club doctors and physiotherapists, an area not previously systematically investigated.

\section{Methods}

The research reported here was undertaken on behalf of the Professional Footballers Association (PFA) and involved semistructured tape recorded interviews of between 30 minutes and one hour with 12 club doctors and 10 club physiotherapists. A total of 19 current and eight former players were also interviewed about their experiences of injury and rehabilitation. Interviews were carried out in the 
second half of the 1997-1998 season and the first half of the 1998-1999 season. Interviewees were given a guarantee that neither they nor their clubs would be identified.

Doctors in the Premier League were more amenable to being interviewed, which probably reflected their generally greater involvement in their clubs. However, this did mean that the sample of doctors interviewed was biased towards those in the Premiership. Of the 12 doctors interviewed, seven were at Premier League clubs, two were with clubs in the First Division of the Nationwide League, two with Second Division clubs, and one with a Third Division club; one Premier club doctor had previously worked in a Second Division club.

In addition to the interviews, a postal questionnaire was sent to 90 club doctors who were not interviewed; 58 questionnaires were returned. The bias towards Premier League club doctors in the interview data was offset by the questionnaire data. Replies were received from 13 Premier League club doctors, 13 First Division club doctors, 15 Second Division club doctors, and 16 doctors at Third Division clubs; one doctor did not indicate the division in which his club played.

Of the physiotherapists who were interviewed, three work in Premier League clubs, two in clubs in the First Division of the Nationwide League, two in Second Division clubs, and two in Third Division clubs; in addition, one physiotherapist had worked in two football clubs (one Third Division club, one Premier League club) but now worked in another sport.

\section{Results}

CLUB DOCTORS

The conditions of employment of club doctors vary greatly from one club to another, but a few generalisations can be made. Firstly, almost all club doctors are appointed on a part time basis; there are only half a dozen or so full time club doctors in England. Secondly, the primary employment of most club doctors is in general practice; of the 56 doctors who answered the relevant question on our questionnaire (there were two non-replies to this question), 42 indicated that general practice is their primary employment. Thirdly, there are substantial variations in the income that doctors receive for their services. Doctors in the higher divisions are normally paid, although the pay is modest. One doctor explained that he received $£ 5200$ a year from the club but that, applying the British Medical Association's recommended scale of charges to the number of hours he worked, he should have been receiving £25000. Clearly, most football clubs are dependent on the goodwill of their doctors and do not offer the rates of pay that doctors would normally expect for their professional services. Doctors at lower division clubs may not receive any payment; the doctor of a Third Division club explained that he actually subsidised the club by providing some medicines and items of equipment from his own general practice surgery. It might also be noted that an important part of the job satisfaction for many club doctors is associated with the fact that they are not just football fans but, in many cases, fans of the particular club for which they work; indeed, this is one of the reasons why most are prepared to work for such modest rates of pay.

Securing an appointment as club doctor is dependent, in the vast majority of cases, on personal contacts. Appointments are hardly ever publicly advertised; of the 55 posts on which we have information from the questionnaire (there were three non-replies to this question), only four were publicly advertised, and only one was advertised in a medical journal. Most doctors (35 out of 55) obtained their positions through personal contact with the previous club doctor; most often, the previous club doctor had been the senior partner in the general practice in which they worked and, when he retired, the post was passed on to a junior partner. Several club doctors inherited the post from a family member, or obtained the post as a result of personal friendship with the club chairman or a club director or someone else connected with the club. The personal friendship, family, and professional ties were sometimes closely interwoven, as in the following case:

"Dad's senior partner was the club doctor when Dad joined the practice and he being very interested in football, went along with the senior partner and sort of acted like a reserve doctor ... when that chap retired he [Dad] took over and one of his friends became the reserve doctor and then when I qualified I took over as reserve doctor and then took over [from Dad] as first team doctor."

Another doctor described how he had obtained the post as a result of his friendship with the previous club doctor, who had himself inherited the post from his uncle. One doctor recognised that the process by which most club doctors are appointed would not generally be regarded as good employment practice:

"I . . am in practice in this area, where the two senior partners had been attached to [the club] since the late 1960s, so it's nepotism. Dead man's shoes."

Although personal ties, professional ties, and family ties were often closely interwoven, occasionally the interpersonal ties were more tenuous, as in the following example, in which a doctor explained how he was appointed at a Premier League club:

Interviewer: "Could you tell me how you got the appointment?"

Doctor: "I was phoned up by [the previous club doctor]. He just said . . . he wanted to retire and was looking for a successor and would I mind coming along and watching a few matches with him as he got to know me." Interviewer: "And you knew him professionally?"

Doctor: "No. I didn't know him at all."

Interviewer: "So why did he contact you?"

Doctor: "I don't know. I think I met his brother at a conference and I think his brother must have spoken to him."

Interviewer: "So you hadn't been involved in sports medicine before?"

Doctor: "No, I hadn't." 
The arrangements under which club doctors were appointed were, as in the above case, often extremely informal. One doctor, a long standing fan of his local club, explained how he was appointed:

"The existing club doctor at the time phoned up and said that he didn't think he could make it to this afternoon's match and asked me if I was going to be there, to which I said 'Yes', and he asked if I wanted to be the official match doctor."

He added that he had not been formally interviewed and had not even formally applied for the post: “There hasn't been an official appointment - there is no correspondence to quote".

This club doctor's experience was not atypical. Of the 58 club doctors who returned the questionnaire, only half (29) had been formally interviewed. Only three were interviewed by a panel that included a doctor, in each case this being the previous club doctor. There can be few other situations within medicine in which an applicant for a medical post would be interviewed by a panel that did not include a medically qualified person; this cannot be regarded as good practice. Those who were interviewed were typically interviewed by the manager, chairman, director, or club secretary. Not surprisingly, the interview did not, indeed could not, take the form of a searching examination of the applicant's clinical knowledge. One club doctor described his interview with the chairman and manager as "very gentle", while another said that for most of his "interview" he simply sat and listened to the chairman's plans for the development of the club! This informality is also reflected in the fact that only six of the 58 doctors surveyed had a written job description. The absence of proper procedures for appointing club doctors is a cause for concern.

The fact that most club doctors are involved more or less full time in general practice limits their experience of, involvement in, and commitment to sports medicine as a specialist area of practice. As noted above, most doctors became involved in their local club when the previous club doctor-often a friend or relative-retired or died, and they were offered the post. Most had no previous experience in sports medicine, and, for most club doctors, this is their one and only involvement in sports medicine. Of the 58 doctors who completed the questionnaire, only eight had ever worked in a sport other than football and only two had ever worked at another football club. Typically, therefore, the club doctor has a very limited experience of sports medicine; he (almost all club doctors are male) is a one sport, one club doctor. His commitment is typically not to sports medicine in general but to his local club, and several doctors indicated that if, for any reason, their contract with their local club were to be terminated, they would not seek employment in another club but would simply return full time to general practice. The absence of a commitment to sports medicine as a career is also evident in some of our other findings: only nine of the 58 doctors who completed the questionnaire have a specialist qualification in sports medicine; only two indicated that their primary employment is in sports medicine; and only six were members of the sports medicine section of the Royal Society of Medicine.

\section{PHYSIOTHERAPISTS}

The position of club physiotherapist, like that of club doctor, is rarely advertised and many appointments are secured on the basis of personal contacts. Of the posts held by the ten club physiotherapists who were interviewed, only one was advertised (in this case, in a national physiotherapy journal). There were considerable variations in the ways in which the physiotherapists were appointed. In three cases, club managers had asked the FA Medical Education Centre at Lilleshall to recommend a physiotherapist. One respondent obtained his post by sending his CV to a club after hearing "on the grapevine" that they needed a physiotherapist. In two cases, physiotherapists were "poached" from smaller clubs by larger clubs; one respondent, describing how he moved from a Third Division club to a Premier League club, explained that after one year at the smaller club he had "one of the classic phone calls that you get in professional football, which was: 'We have not had this conversation, but if our physiotherapist leaves at the end of this season, would you be interested in working for us?" ". Another physiotherapist explained how he moved from a Third Division to a First Division club:

"The manager of [the First Division club] just rang me and said 'I fancy a change' [of physiotherapist] . . . it was totally illegal . . . he'd got rid of his physio, had left for whatever reason. It was a female actually. I think pressure from the Board. I know it's sexist, but pressure from the Board . . . He spoke to various people and I think I was doing a decent job at [my previous club] ... I think he probably said 'I am looking for a physio' and someone said 'have you heard about the chap at [my previous club]?" ".

This is a good example of what one physiotherapist described as getting a job "through the old boy network of 'I know somebody who, etc.'".

This "old boy network" is associated with a second characteristic of the appointment process, which is that the job of club physiotherapist is often in the gift of the manager. One example was provided by a physiotherapist (an explayer) who explained that, after working abroad for some time, he returned to England and a former playing colleague who was now a manager heard that he was back in the country, phoned him, and offered him the job as club physiotherapist. There was no formal job application and no interview; the job was offered and accepted over the phone. After this interview, the interviewer had a brief conversation with the club groundsman, who had been formally interviewed-a "jacket and tie job", as he put it - by the club chairman. It is disturbing that the person who looked after the pitch was interviewed, while the person who treated the players' injuries was not.

It is not unusual for managers, when changing clubs, to take some of their previous "back- 
room staff", including the physiotherapist, to their new club. This is sometimes a cause for concern. Two doctors indicated that problems had arisen as a result of a new manager bringing in a non-chartered physiotherapist from his former club. In one of these cases, the physiotherapist had only a much lower level qualification in sports therapy. The doctor explained:

"I wasn't involved in choosing him and I wasn't desperately happy with that situation ... I suppose I had hoped that having been here for a while they might consult me . . . it just happened very, very quickly and so it was difficult because when the manager suggested this guy who he'd actually worked with beforethat was the connection-I said, 'That's fine'. He said, 'It's this great physio. He works really hard and he'll be fantastic'. I never thought to question when somebody said the physio was ... very, very good and very experienced, that he wasn't chartered. Which was my mistake. By the time I met him and said, 'Where did you train?' and he said he'd done the Sports Therapy Course, he'd already sold his house ... and arranged to move ... he knew I wasn't comfortable with him but, at the same time, the appointment had been made."

In another club, the doctor explained that in recent years, the club's physiotherapists had all been chartered, with just one exception. The exception was a non-chartered physiotherapist brought in by a new manager:

"We've always had chartered physios. It was only that one ... because the manager came in and insisted on bringing his physio from this other club ... I said at the time I would rather have a chartered physio ... the manager got his way but that appointment was not successful ... and from that came the fact that I would sit on the interview committee and then interview any new physios and have a say in who was appointed, which I find more satisfactory."

The club now had a chartered physiotherapist once again; the doctor explained how this had affected the pattern of medical work at the club:

"In the past, players have come to me without going through the physio if they haven't been happy with the physio . . . that has happened, but this physio isn't that sort of problem ... At the moment, I just see the players he wants me to look at. He's only been appointed this season and up until this season I would always religiously go in every week and see everybody who was injured, but that was a different physio and he wasn't as well qualified so I was happier seeing absolutely everybody and making sure everything was going along. This physio's far more confident and better qualified so he will like this week - it's all quiet so he says at the moment there's no need for me to go in so I won't even go in this week."

It may be significant that both doctors were relatively young, and one was one of the relatively few club doctors with a specialist qualification in sports medicine; it may be that younger and better qualified doctors are becoming more demanding about issues concerning the quality of care in football clubs. Nevertheless, these two cases do highlight a problem concerning the appointment of club physiotherapists, namely that it is not normal practice for the club doctor to be consulted about the appointment of the physiotherapist; the appointment is usually made informally, often without interview, and often by the manager without involving anyone who is qualified in medicine or physiotherapy; this cannot be regarded as good practice.

The questionnaire sent to club doctors included a question about the qualifications of the senior physiotherapist at the club; of 53 physiotherapists on whom we have information (five doctors did not answer this question), 27 were chartered physiotherapists, while 26 were not chartered, the most common qualification held by non-chartered physiotherapists being the FA diploma (held by 23 of the 26 non-chartered physiotherapists). Chartered physiotherapists are more likely to be found in clubs in the Premier League and First Division of the Nationwide League; of the 13 Premier League club physiotherapists on whom we have data, 11 are chartered. In the First Division of the Nationwide League, six out of 11 are chartered, in the Second Division, five out of 15, and in the Third Division, five out of 14 . Overall, in half of the professional football clubs in England, the day to day management of injuries is in the hands of people who are not qualified to work as physiotherapists within the NHS. This raises serious questions about the quality of care.

\section{Discussion}

Almost all aspects of the processes of appointing and remunerating club doctors and physiotherapists need careful re-examination; currently, these processes constitute a catalogue of poor employment practice. The limited qualifications and experience of many club doctors are also matters of concern. Paying a very modest fee to a local general practitioner, who has no experience of sports medicine but who happens to be a fan of the club and who is recruited on the basis of personal or family contact, may be a cheap and easy way of appointing a club doctor but it has little else to commend it and it is unlikely to be in the best long term interests of the club or the players.

A number of questions are also raised about the qualifications and experience of physiotherapists. Most of the physiotherapists who hold the FA diploma are ex-players, and many have spent the whole of their working lives within the world of professional football. This is claimed by some people within football as an advantage; one non-chartered physiotherapist argued that chartered physiotherapists "have never played the game . . . they don't know what it's like, they don't know what the players are going through ... I feel that I have a little advantage over the chartered people in as much as I have played the game". However, whatever advantages the ex-player with an FA diploma may have over his chartered counterpart, these are more than offset by several important disadvantages in terms of the quality of care that he is likely to be able to offer.

The problems here relate not just to the fact that non-chartered physiotherapists have a much lower level qualification than chartered physiotherapists, although this is itself a matter of concern. There are also other problems. Firstly, in the course of the research, it became 
clear that many players - probably a majorityare not registered with a general practitioner outside the club or, if they are, they rarely use $\mathrm{him} / \mathrm{her}$; indeed, in one club with a small playing staff, players were actively discouraged from using a general practitioner outside the club because it was feared that an outside general practitioner may too easily agree to their having time off when sick, thus depleting the club's limited squad of players. This is, in itself, a matter of concern; it is important that players should have routine access to medical advice that is independent of that provided by their employer. The research also indicated that many players use the club doctor and, particularly in lower division clubs where the club doctor may not come in regularly during the week, also the club physiotherapist as, in effect, primary care practitioners to whom they bring problems relating not only to injury but also to illness. In such situations, the very limited knowledge that FA trained physiotherapists have about more general health matters is a cause for concern. One doctor expressed this concern thus:

"Footballers, however often you tell them, especially younger footballers, don't register with other GPs. They don't have any other access to health care, they tend to go straight to the physio with anything ... my worry would be that if an 18 year old lad comes in and says 'I've got a dreadful headache' . . . they're sent home with a couple of paracetamol and really they've got meningitis. I think a broader range of experience is quite important for the physio."

This broader range of experience of the chartered physiotherapist is also important for other reasons. Leaving aside the different levels of qualification, perhaps the most important difference between non-chartered and chartered physiotherapists is that the latter will have carried out part of their training, and will probably have spent some of their professional lives, within the NHS and perhaps also in private practice. In these contexts, they will have absorbed the culture of a health care system in which their work will have been subject to the scrutiny of their seniors and their peers, and in which there are relatively well established criteria of what constitutes good quality care, both in terms of technical and ethical considerations. By contrast, ex-players who have taken the FA diploma are likely to have spent much, or even all, their working lives within football and will have absorbed the culture, not of the health care system, but of professional football. The standards of care with which they will be familiar will not be the clinical and ethical standards that apply within the health service, but those that derive from the culture of professional football, some aspects of which, notably the strong constraints on players to "play hurt"- that is, to continue to play with injury and pain, if necessary with the help of pain killing injections and even if this risks further damage-are not conducive to good clinical practice. It is not suggested that ex-players who have become physiotherapists knowingly cut corners in terms of quality of care; however, they have not had the same exposure as chartered physiothera- pists to the generally higher standards of clinical and ethical care expected of those who work within the NHS, and they have no knowledge of standards of care other than those that apply within football. In this context it was noticeable that, although the sample of physiotherapists interviewed was quite small (of the ten physiotherapists, six were chartered and four not chartered), there did appear to be an appreciable tendency for chartered physiotherapists to be more critical of the quality of care offered within professional football.

There is a further related problem in relation to non-chartered physiotherapists. As the report prepared for the PFA clearly documents, ${ }^{13}$ playing with pain, or when injured, is a central part of the culture of professional football. ${ }^{15}$ Managers look for players who have what, in professional football, is regarded as a "good attitude", and one way that players can show that they have such an attitude is by being prepared to play when injured. If the risks of playing while injured, or with pain killing injections, are fully explained to players and if, after being given this information, they choose to play, then this does not of itself raise any ethical problems. However, different problems arise when coaches/managers insist on becoming involved in the treatment process. Such situations were described by several club physiotherapists (and doctors) all of whom indicated that such managerial interventions are, almost invariably, unhelpful. In extreme situations, the clinical autonomy of physiotherapists and doctors may be undermined; they may find themselves marginalised and their advice ignored, while players are regularly returned to play before they are medically fit to do so, only to break down almost immediately. Physiotherapists who are not chartered, who are not familiar with standards of practice outside of football, and who, most importantly, are not qualified to work outside of football are in a weak position to resist such threats to their clinical autonomy. Chartered physiotherapists, by contrast, are not only more likely to have a clearer idea of what constitutes a satisfactory standard of professional care but they are in a better position to resist threats to their autonomy, not least because they can find alternative employment outside of football.

In the light of our findings we recommend the following.

(1) All vacancies for club doctors and physiotherapists should be publicly advertised in appropriate professional journals.

(2) Applicants should be provided with a clear written job description and a personnel specification listing essential and desirable candidate attributes.

(3) All short listed candidates should be formally interviewed.

(4) Possession of a specialist qualification in sports medicine (or the willingness to undertake a course of study leading to a specialist qualification) should be specified as a desirable (although not, in the short term, essential) attribute of candidates for the post of club doctor. 
(4) At least one independent medical practitioner-that is, one having no connection with the club-with expertise in sports medicine should be involved in the selection and interviewing of candidates for the post of club doctor. The National Sports Medicine Institute or a similar body could be asked to nominate an appropriate person to join the appointing panel.

(5) Clubs should assist club doctors to take a relevant specialist qualification, if they do not already have one. In smaller clubs, this could involve financial assistance with course fees; in wealthier clubs it could involve assistance in paying for a locum to cover attendance at courses.

(6) Qualification as a chartered physiotherapist should be specified as an essential requirement for all newly appointed club physiotherapists.

(7) Club doctors should be fully involved in the short listing and interviewing of candidates for the post of physiotherapist.

(8) Physiotherapists with a lower qualification-for example, the FA diploma-could be appointed as assistant physiotherapists but should only be allowed to work under the direction of a chartered physiotherapist.

This research was carried out on behalf of the Professional Footballers Association, who part funded the research. The research was also part funded by the Social Sciences Research Committee at Leicester University.

1 Cantu RC, Lyle JM (eds). ACSM'S guidelines for the team physician. Philadelphia and London: Lea and Febiger, physician.

2 Mellion MB, Walsh WM. The team physician. In: Mellion $\mathrm{MB}$, ed. Sports medicine secrets. Philadelphia: Hanley and Belfus, 1994:1-4.

3 Lynch JM, Carcasona CB. The team physician. In: Ekblom $\mathrm{B}$, ed. Handbook of sports medicine and science: football (soccer). Oxford: Blackwell Scientific Publications, 1994: 166-74.

4 Crane J. Association Football: the team doctor. In: Payne SDW, ed. Medicine, sport and the law. Oxford: Blackwell Scientific Publications, 1990:331-7.

5 Macleod DAD. Team doctor. The role of doctor to the Scottish rugby team and also the British Lions. Br F Sports Med 1989;23:211-12.

6 Kennedy KW. The team doctor in Rugby Union football. In: Payne SDW, ed. Medicine, sport and the law. Oxford: Blackwell Scientific Publications, 1990:315-23.

7 Davies J. The team doctor in international rugby. In: Payne SDW, ed. Medicine, sport and the law. Oxford: Blackwell Scientific Publications, 1990:324-30.

8 Smith FW. Where is the crowd doctor? Br f Sports Med 1998;32:198.

9 Dodds RDA. What does a team expect from its doctor? $\mathrm{Br} \mathcal{F}$ Sports Med 1989;23:145-6.

10 Rubin A. Team physician or athlete's doctor? Physician and Sportsmedicine 1998,26:27-9.

11 Macauley D. Will money corrupt sports medicine? $\mathrm{Br} \mathcal{F}$ Sports Med 1997;32:1.

12 Graf-Baumann T. The law and ethics of football injuries. FIFA Magazine. 1997 Feb:31.

13 Waddington I, Roderick M, Parker G. Managing injuries in professional football: the roles of the club doctor and physiotheraprofessional football: the roles of the club doctor and physiothera-
pist. Leicester: Centre for Research into Sport and Society, pist. Leicester: Centre for Researc
University of Leicester, 1999.

14 Waddington I. Sport, health and drugs. London: E and FN Spon, 2000:59-86.

15 Roderick M, Waddington I, Parker G. 'Playing hurt'. International Review for the Sociology of Sport 2000;35:16580 .

\section{Take home message}

Almost all aspects of the processes of appointing and remunerating club doctors and physiotherapists need careful re-examination; currently, these processes constitute a catalogue of poor employment practice. The limited qualifications and experience of many club doctors and physiotherapists are also matters of concern.

\section{Commentary}

This paper highlights several areas of concern about the appointment of doctors and physiotherapists to professional football clubs. As this research was part funded by the Professional Footballers Association, it seems that this body shares these concerns.

Professional football is a multimillion pound industry, with players often being transferred between clubs for many millions of pounds, and top players earning vast sums of money on a weekly basis. That the medical care of these players is often handed down between generations or through the "old boy" network is a matter of concern. Appointment of club doctors should be made on a competitive basis using the same strict guidelines that apply to doctors employed within the NHS and industry. A relevant postgraduate qualification should be an essential prerequisite.

It is a fallacy to believe that you have to have played the game to make a good football physiotherapist. Experience is vital in all areas of employment, but bad habits can easily become ingrained in an environment like soccer, where it is the "macho" thing to play through an injury. Surely in an age when many top clubs are quoted on the Stock Exchange, it should not be long before the "money men" wake up to the fact that they may not be properly guarding their most valuable assets, the players. 